\title{
Durability of fluoropolymer and antibacterial finishes on woven surgical gown fabrics
}

Vinay Kumar Midha ${ }^{1 *}$, Ravikant Vashisht ${ }^{1}$ and Varsha Midha ${ }^{2}$

\author{
* Correspondence: \\ midhav@rediffmail.com \\ 'Department of Textile Technology, \\ National Institute of Technology, \\ Jalandhar, India \\ Full list of author information is \\ available at the end of the article
}

\begin{abstract}
Commercially available polyester, polyester-cotton and cotton plain woven fabrics of $150 \mathrm{~g} / \mathrm{m}^{2}$ weight and cotton woven fabric samples of $200 \mathrm{~g} / \mathrm{m}^{2}$ weight with plain, twill and satin weave were studied for their suitability as surgical gowns. Water repellent and anti bacterial finishes were applied in single bath using pad-dry-cure method with four concentration levels of these finishes. Liquid barrier properties of samples were analyzed by water impact penetration and hydrostatic pressure test. Parallel streak method was used to measure the antibacterial activity on the fabric samples with Staphylococcus aureus. The fabric samples were also analyzed for air permeability and stiffness. Optimum concentration level of fluoropolymer and antibacterial finishes for achieving desired liquid barrier and antibacterial properties were determined for each fabric samples. Fabric samples were subjected to repeated laundering cycles to evaluate the durability of finishes. It was observed that polyester fabric samples and $200 \mathrm{~g} / \mathrm{m}^{2}$ cotton twill woven fabrics show highest level of liquid barrier protection of Level 2 according to Association for the Advancement of Medical Instrumentation (AAMI) standards, with 4\% and $7 \%$ fluoropolymers. The fabrics maintain their barrier protection upto 20 laundering cycles, whereas 100\% cotton fabric samples show minimal liquid barrier protection and do not provide Level 2 protection even at 4\% and 7\% fluoropolymer.
\end{abstract}

Keywords: Air permeability; Antibacterial; Fluoropolymer; Hydrostatic; Staphylococcus aureus; Water repellency

\section{Introduction}

Surgical gowns address a dual function of preventing transfer of microorganism and body fluids from operating staff to the patient and also from patient to operating staff (CDC 1998; Huang \& Leonas 2000; Laufman et al. 1979; Slater 1998). Several organizations like Centers for Disease Control and Prevention (CDC), Association of Peri-operative Registered Nurses (AORN), Occupational Safety and Health Administration (OSHA), The Operating Room Nurses Association of Canada (ORNAC), and the Association for the Advancement of Medical Instrumentation (AAMI) have made recommendations on how to protect surgical staff as well as patients from exposure to blood borne pathogens and bacteria (AAMI 2003; Slater 1998). AAMI standard, PB70:2003 provides four classification levels for barrier performance of surgical gowns (Table 1). Using these classification levels, manufacturers are able to label their products according to the level of protection provided and healthcare workers are able to identify the level of protection that the product provides, so they may choose the appropriate barrier needed for their procedure. A wide range of

(c) 2014 Midha et al.; licensee Springer. This is an Open Access article distributed under the terms of the Creative Commons Attribution License (http://creativecommons.org/licenses/by/4.0), which permits unrestricted use, distribution, and reproduction in any medium, provided the original work is properly credited. 
Table 1 AAMI classification levels

\begin{tabular}{lccc}
\hline \multicolumn{4}{c}{ AAMI classification levels } \\
\hline Level & Test & Result & Test \\
\hline 1 & AATCC 42 & $\leq 4.5 \mathrm{~g}$ & Impact penetration test \\
2 & AATCC 42 & $\leq 1 \mathrm{~g}$ & Impact penetration test \\
& AATCC127 & $\geq 20 \mathrm{~cm}$ & Hydrostatic pressure test \\
3 & AATCC 42 & $\leq 1 \mathrm{~g}$ & Impact penetration test \\
& AATCC127 & $\geq 50 \mathrm{~cm}$ & Hydrostatic pressure test \\
4 & ASTM F1670 & Pass & Synthetic blood test \\
& ASTMF1671 & Pass & Bacteriophage test \\
\hline
\end{tabular}

disposable (single-use), reusables and reinforced surgical gowns are available (Behera and Arora 2009; Garibaldi et al. 1986; Lankester et al. 2002; Laufman et al. 1975; Leonas and Jinkins 1997; Leonas 1998; Olderman 1984; Pamuk et al. 2009; Parthasarathi and Thilagavathi 2011; Rutala and Weber 2001; Smith and Nichols 1991; Virk et al. 2004). Disposable surgical gowns offer several advantages over reusables, but they are expensive and pose a risk of contamination outside of the hospital setting. Reusable gowns are generally made from woven fabrics and often contain cotton, polyester or a blend of these two fibres. The reusable surgical gowns are laundered and sterilized after every use in order to remove stains and kill bacteria. The greater advantage with reusable surgical gowns include less solid waste from limited disposal and more comfort to the wearer because of their better water vapour transmission. However they lose durability and barrier protection after repeated washing (Laufman et al. 1975). Several researchers reported that water repellency and antibacterial resistance can be improved by applying water repellent and antibacterial finishes to the fabric (Brock et al. 1994; Garibaldi et al. 1986; Gupta 1998; Laufman et al. 1975; Leonas and Miller 1990; Leonas 1997; Leonas, 1998; Leonas and Jinkins, 1997; Olderman 1984; Smith and Nichols 1991; Midha et al. 2012). Fluorocarbon-based finishes are most commonly used in protective apparels for reducing the surface energy of the fabric sufficiently to repel both water and oil-based liquids.

In this paper, different concentration levels of fluoropolymer and antibacterial finishes were applied on woven fabrics of different weave and fibre content. Their performance with respect to barrier resistance, air permeability and stiffness has been studied. The fabrics were subjected to repeated laundering cycles for evaluating the durability of water repellent and antibacterial finishes.

\section{Methods}

Plain, twill, satin woven fabrics with different weaves and area density were used in the study. Fabrics A-C are plain weave structures of $150 \mathrm{~g} / \mathrm{m}^{2}$ made from different fibre materials but almost same mean flow pore diameter. Sample D-F are $200 \mathrm{~g} / \mathrm{m}^{2}$ cotton fabrics with different weave structures (Table 2) and hence different pore diameter.

A fluoropolymer 'Clarient Nuva SRCN liq' was used to impart the liquid repellent properties. 'Zydex Zycrobial' non-leaching type antibacterial finish, a quaternary ammonium salts based compound was used to impart antibacterial properties on surgical gowns.

Water repellent and antibacterial finishes were applied on the fabric samples in a single bath after checking their compatibility. Three concentration levels of 
Table 2 Characteristics of fabric samples

\begin{tabular}{lccccccccc}
\hline Sample & $\begin{array}{c}\text { Fibre } \\
\text { composition }\end{array}$ & $\begin{array}{c}\text { Fabric } \\
\text { weight } \\
\left(\mathbf{g} / \mathbf{m}^{2}\right)\end{array}$ & Weave & $\begin{array}{c}\text { Warp } \\
\text { density } \\
\text { (ends/cm) }\end{array}$ & $\begin{array}{c}\text { Weft } \\
\text { density } \\
\text { (picks/cm) }\end{array}$ & $\begin{array}{c}\text { Warp } \\
\text { linear } \\
\text { density } \\
\text { (Tex) }\end{array}$ & $\begin{array}{c}\text { Weft } \\
\text { linear } \\
\text { density } \\
\text { (Tex) }\end{array}$ & $\begin{array}{c}\text { Fabric } \\
\text { thickness } \\
\text { (mm) }\end{array}$ & $\begin{array}{c}\text { Mean } \\
\text { flow pore } \\
\text { diameter } \\
\text { (microns) }\end{array}$ \\
\hline A & $100 \%$ PET & 150 & Plain & 356 & 538 & 8 & 12 & 0.232 & 46.09 \\
B & $65 / 35$ PC & 150 & Plain & 249 & 173 & 24 & 24 & 0.300 & 42.87 \\
C & $100 \%$ cotton & 150 & Plain & 325 & 157 & 20 & 20 & 0.304 & 47.72 \\
D & $100 \%$ cotton & 200 & Plain & 290 & 173 & 30 & 20 & 0.582 & 30.27 \\
E & $100 \%$ cotton & 200 & 2/1Twill & 320 & 203 & 20 & 30 & 0.531 & 26.84 \\
F & $100 \%$ cotton & 200 & 5 Ends & 457 & 234 & 17 & 20 & 0.500 & 62.97 \\
\hline
\end{tabular}

*Note: PC- Polyester cotton blend.

fluoropolymer finish (i.e. $1 \%, 4 \%$ and $7 \%$ on weight of fibre) were co-applied with $1 \%$, $1.5 \%$ and $3 \%$ (on weight of fibre) of antibacterial finish. The pad dry cure process was used for the application of finishes. The fabric samples were immersed in the stock solution prepared according to the required concentration levels, followed by padding through squeezed rollers to get $70 \%$ wet pick-up. After padding, the fabrics were dried at $90^{\circ} \mathrm{C}$ and then cured at $140-150^{\circ} \mathrm{C}$ for two minutes. The treated and untreated fabric samples were tested for water repellence, antibacterial activity, air permeability and stiffness.

Impact penetration test was performed according to the AATCC 42, wherein $500 \mathrm{ml}$ of distilled water was poured on standard blotter paper of $152 \times 230 \mathrm{~mm}$ inserted beneath the $178 \times 330 \mathrm{~mm}$ test specimen on an inclined surface. The amount of water passing through the fabric is given by the change in weight of the blotting paper, which is used as an indication of water repellence of fabric. Five readings were taken and the average calculated. Hydrostatic pressure test was performed according to AATCC-127 to measure the force required by water to penetrate through a textile material under a water pressure constantly increasing at $10 \pm 0.5 \mathrm{~cm}$ per minute, until three leakage points appear on its surface. Five readings were taken and the average calculated.

Parallel streak method was used to determine the antibacterial property of the fabric samples according to AATCC 147. Staphylococcus aureus, a pathogenic gram positive bacterium was used in the study, since it is most commonly present in human body fluids. In this test, five streaks of $S$. aureus were inoculated onto nutrient agar plate approximately $60 \mathrm{~mm}$ in length, spaced $10 \mathrm{~mm}$ apart covering the central area of Petri dish without refilling the loop. The fabric specimen of $40 \mathrm{~mm}$ diameter was placed in intimate contact with the agar previously streaked with the inoculums of S.aureus. The plate was incubated at a temperature of $37^{\circ} \mathrm{C}$ for 24 hours. After incubation, a clear area of interrupted growth underneath and along the sides of the test material indicates antibacterial activity of the specimen. Five readings were taken for each sample.

Air permeability of fabric samples was measured by Textest air permeability tester according to ASTM standard D737. The air permeability was measured as volume of airflow in cubic centimetres passed per second through $1 \mathrm{~cm}^{2}$ of the fabric at a pressure of $98 \mathrm{~N} / \mathrm{m}^{2}$. The $20 \times 20 \mathrm{~cm}^{2}$ specimen was clamped on the holder in such a way that a $5 \mathrm{~cm}^{2}$ area, exposed to test is sufficiently away from the edges in order to avoid the edge leakage. Ten readings were taken and the average calculated. The stiffness of the fabric samples was measured on Shirley stiffness tester using circular bend test method according to ASTM D4032. The maximum force required by a plunger $(25.4 \mathrm{~cm}$ diameter) to force a flat, folded fabric swatch through an orifice (of $38.1 \mathrm{~mm}$ in a platform of 
$102 \mathrm{~mm} \times 102 \mathrm{~mm} \times 6 \mathrm{~mm}$ ) for a stroke length of $57 \mathrm{~mm}$ is an indication of the fabric stiffness. Ten readings were taken and the average calculated.

Fabric thickness was measured by Shredor thickness gauge according to ASTM standard D5736 and weight of fabric was determined according to ASTM standard test method D3776 using an electronic balance. Ten readings were taken and the average calculated. Mean flow pore diameter was measured according to ASTM standards D6767 on 'PMI Capillary flow porometer (CFP- $1100 \mathrm{AN}$ )' using a sample size of $2.5 \mathrm{~mm}$ diameter. Five readings were taken and the average calculated.

The treated fabric samples were subjected to 1, 5, 10, 15 and 20 laundering cycles to check the durability of finishes with laundering cycles. Laundering was performed according to AATCC Test Method 124-2007. Wash settings were hot wash $\left(62 \pm 3^{\circ} \mathrm{C}\right)$, large load (18 \pm 1 gallons of water), warm rinse $\left(41 \pm 3^{\circ} \mathrm{C}\right)$ and regular spin. The fabric samples were washed with $1 \frac{1}{2}$ cups of detergent 'Tide' for $10 \mathrm{~min}$. The samples were subsequently air-dried at room temperature and heat-pressed. Heat pressing helps in partially restoring the liquid repellence lost during laundering. Statistical significance tests were performed to check the effect of fabric material, fabric weave, level of antibacterial and fluoropolymer finishes on the fabric barrier properties.

\section{Results and discussions}

The fabric samples were tested for water repellence, antibacterial acitivity, air permeability and stiffness force before and after applying different concentration levels of fluoropolymer and antibacterial finishes.

\section{Water repellence}

Table 3 shows the liquid barrier and antibacterial characteristics of untreated fabric samples. It is observed that among $150 \mathrm{~g} / \mathrm{m}^{2}$ plain fabrics (i.e. sample A, B and C), the weight of water penetrating through the fabric during impact penetration is highest for $100 \%$ cotton fabric and least for $100 \%$ polyester fabrics. Similarly, the hydrostatic pressure head value is least for $100 \%$ cotton and highest for $100 \%$ polyester fabric. The results are statistically significant at $95 \%$ confidence level. The polyester fabric shows highest water repellence, whereas $100 \%$ cotton fabric shows least water repellence due to lower surface tension of polyester fibres as compared to cotton fibres. Cotton fibres immediately absorb water and therefore the fabrics offer least water repllence. According AAMI barrier performance classification, all the fabrics except $100 \%$ cotton fabric of $150 \mathrm{~g} / \mathrm{m}^{2}$ (i.e. fabric C) can be used for level 1 protection only. $100 \%$ cotton $150 \mathrm{~g} / \mathrm{m}^{2}$ fabric is not suitable for even level 1 protection for surgical gowns.

Table 3 Properties of untreated fabric samples

\begin{tabular}{llllll}
\hline Sample & $\begin{array}{l}\text { Impact } \\
\text { penetration }(\mathbf{g})\end{array}$ & $\begin{array}{l}\text { Hydrostatic } \\
\text { pressure } \mathbf{( c m})\end{array}$ & $\begin{array}{l}\text { Antibacterial } \\
\text { activity }\end{array}$ & $\begin{array}{l}\text { Air permeability } \\
\left(\mathbf{c m}^{\mathbf{3}} / \mathbf{c m}^{2} / \mathbf{s e c}\right)\end{array}$ & $\begin{array}{l}\text { Stiffness } \\
\text { force (N) }\end{array}$ \\
\hline A & 1.53 & 6.5 & Fail & 6.62 & 1.05 \\
B & 1.72 & 5.3 & Fail & 6.17 & 1.02 \\
C & 4.97 & 4.5 & Fail & 5.86 & 1.10 \\
D & 0.97 & 6.0 & Fail & 4.67 & 2.43 \\
E & 0.73 & 9.0 & Fail & 2.98 & 2.90 \\
F & 1.17 & 4.3 & Fail & 13.29 & 2.10 \\
\hline
\end{tabular}


Table 4 Liquid barrier properties of treated fabric samples

\begin{tabular}{|c|c|c|c|c|c|c|c|c|c|c|c|c|c|c|}
\hline \multicolumn{3}{|c|}{ Experimental conditions } & \multicolumn{6}{|c|}{ Impact penetration (g) } & \multicolumn{6}{|c|}{ Hydrostatic pressure $(\mathrm{cm})$} \\
\hline & $\begin{array}{l}\text { Antibacterial } \\
\text { finish (\%) }\end{array}$ & $\begin{array}{c}\text { Water } \\
\text { repellent } \\
\text { finish (\%) }\end{array}$ & A & B & $\mathrm{C}$ & D & E & $F$ & A & B & C & D & E & $\mathrm{F}$ \\
\hline 1. & 0 & 1 & 0.91 & 1.32 & 3.51 & 0.56 & 0.42 & 0.86 & 14.5 & 14.0 & 7.9 & 17.0 & 18.5 & 15.5 \\
\hline 2. & 0 & 4 & 0.70 & 0.68 & 2.54 & 0.45 & 0.31 & 0.54 & 22.5 & 20.6 & 13.6 & 25.3 & 28.5 & 20.5 \\
\hline 3. & 0 & 7 & 0.49 & $0.64^{*}$ & 1.30 & 0.35 & 0.24 & 0.43 & 25.7 & 22.9 & 16.1 & 27.0 & 32.7 & 22.3 \\
\hline 4. & 1 & 1 & 0.96 & 1.29 & 3.27 & 0.53 & 0.41 & 0.81 & 15.2 & 13.9 & 9.3 & 18.2 & 19.0 & 16.5 \\
\hline 5. & 1 & 4 & 0.72 & 0.61 & 2.52 & 0.41 & 0.27 & 0.55 & 23.2 & 21.4 & 14.7 & 25.8 & 29.5 & 21.0 \\
\hline 6. & 1 & 7 & 0.46 & 0.53 & 1.30 & 0.29 & 0.24 & 0.38 & 26.6 & 23.5 & 16.8 & 27.8 & 32.3 & 22.9 \\
\hline 7. & 1.5 & 1 & 0.96 & 1.06 & 3.12 & 0.47 & 0.37 & 0.84 & 15.5 & 15.3 & 9.5 & 17.9 & 19.0 & 16.5 \\
\hline 8. & 1.5 & 4 & 0.64 & 0.59 & 2.30 & 0.39 & 0.28 & 0.51 & 24.4 & 22.3 & 15.1 & 25.9 & 29.5 & 21.4 \\
\hline 9. & 1.5 & 7 & 0.41 & 0.56 & 1.19 & 0.28 & 0.25 & 0.36 & 28.0 & 23.9 & 17.1 & 27.8 & 34.7 & 23.1 \\
\hline 10. & 3 & 1 & 0.89 & 0.90 & 3.16 & 0.43 & 0.36 & 0.76 & 16.1 & 15.9 & 10.3 & 18.7 & 19.5 & 17.3 \\
\hline 11. & 3 & 4 & 0.57 & 0.54 & 2.01 & 0.36 & 0.24 & 0.39 & 26.6 & 23.0 & 15.7 & 26.0 & 29.0 & 22.0 \\
\hline 12. & 3 & 7 & 0.42 & $0.53^{*}$ & 1.03 & 0.23 & 0.21 & 0.30 & 29.7 & 24.2 & 17.5 & 29.0 & 36.0 & 24.0 \\
\hline 13. & 1 & 0 & 1.56\# & 1.69\# & 4.57 & 0.89 & $0.59^{*}$ & 1.03 & $6.8 \#$ & 6.1 & $5.5^{*} \#$ & 5.8\# & $9.2 \#$ & 4.9 \\
\hline 14. & 1.5 & 0 & 1.49\# & $1.62^{*}$ & 4.49 & $0.82^{*}$ & $0.58^{*}$ & 0.96 & $6.9^{*} \#$ & 7.1 & $5.4^{*} \#$ & $6.7^{* \#}$ & $9.0^{* \#}$ & $4.8^{*}$ \\
\hline 15. & 3 & 0 & $1.43^{*}$ & 1.54 & 4.23 & $0.79^{*}$ & $0.54^{*}$ & 0.91 & $7.7^{*}$ & $7.2^{*}$ & $6.3^{*}$ & $8.0^{*}$ & 11.1 & 5.7 \\
\hline 16. & 0 & 0 & 1.53 & 1.72 & 4.97 & 0.97 & 0.73 & 1.17 & 6.5 & 5.3 & 4.5 & 6.0 & 9.0 & 4.3 \\
\hline
\end{tabular}

Note: '*' means results are statistically insignificant at $95 \%$ confidence level with respect to finish level \& ' $\#$ ' means results are with respect to untreated fabric.

Table 4 shows the results for samples treated with fluoropolymer (1\%, $4 \%$ and $7 \%)$ and antibacterial finish $(1 \%, 1.5 \%$ and $3 \%)$. It is observed that, impact penetration decreases and hydrostatic pressure increases with increase in concentration level of fluoropolymer at all levels of antibacterial finish.

Application of fluoropolymer finish reduces the surface energy of the fabric and does not permit the water or other fluids to adsorb and spread on the fabric surface. The difference in water repellence is significant at $1 \%$ and $4 \%$ concentration level of fluoropolymer, but when the concentration level increases to $7 \%$, the difference is insignificant, which may be due to the fact that the fluoropolymer has already linked with functional groups of the polymer. $100 \%$ polyester and polyester cotton fabrics treated with $4 \%$ and 7\% fluorpolymer reach hydrostatic pressure level of more than $20 \mathrm{~cm}$ and therefore can be used for level 2 protection as per AAMI barrier classification, whereas $100 \%$ cotton fabric can provide only level 1 protection even on application of $7 \%$ fluoropolymer finish.

Among plain, twill and satin cotton fabric samples of $200 \mathrm{~g} / \mathrm{m}^{2}$ (i.e. sample D, E and F), twill fabrics offer highest water repellence with least impact penetration and highest hydrostatic pressure, whereas satin woven structure offers the least water repellence. The trend is same even after the application of fluoropolymer and antibacterial finish. The results are statistically significant at $95 \%$ confidence level. Longer float in the satin weave inspite of finer yarns and higher yarn density, leads to larger pore size $(62.97 \mu \mathrm{m})$ and long capillary formation that enhance the movement of the liquid through the fabric (Tables 2 and 3). Plain and twill fabric have smaller pore sizes of the order of $26-30 \mu \mathrm{m}$. The plain weave with its simple and regular interlacing pattern is susceptible to capillary forces that enhance the movement of the liquid through the fabric. Whereas in twill fabrics, the orientation of the yarns or fiber to 


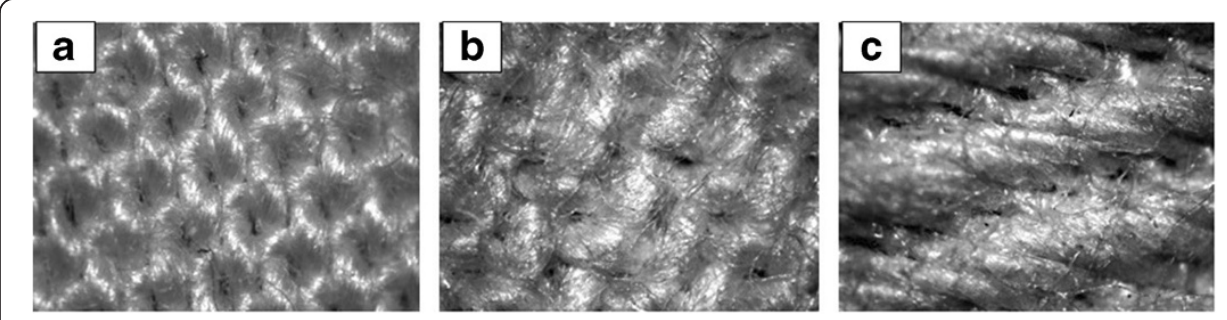

Figure 1 Microscope images of $100 \%$ cotton woven fabric samples of $200 \mathrm{~g} / \mathrm{m}^{2}$ : (a) plain, (b) twill and (c) satin.

one another is disrupted; capillaries are shorter, which reduce the liquid flow. Figure 1 shows the microscopic images of these fabrics.

All the fabrics provide level 2 protection as per AAMI barrier classification after application of $4 \%$ and $7 \%$ fluoropolymer finish. The highest level of hydrostatic pressure achieved is $36 \mathrm{~cm}$ by the twill woven fabric after application of 7\% fluoropolymer finish.

$200 \mathrm{~g} / \mathrm{m}^{2}$ plain woven cotton fabric shows higher hydrostatic pressure than $150 \mathrm{~g} / \mathrm{m}^{2}$ weight of fabric at all concentration levels of fluoropolymer. Thicker yarns in the heavier fabric are responsible for smaller pores and hence better water repellence as compared to lighter fabrics (Table 2). Table 5 shows the effect of laundering on hydrostatic pressure for fabric samples which passed AAMI barrier protection level two. It is observed that $100 \%$ polyester plain woven fabric of $150 \mathrm{~g} / \mathrm{m}^{2}$ weight treated with $7 \%$ fluoropolymer maintains its liquid barrier properties for AAMI level-2 protection up to 20 washing cycles. $150 \mathrm{~g} / \mathrm{m}^{2}$

Table 5 Effect of laundering on hydrostatic pressure of fabric samples

\begin{tabular}{|c|c|c|c|c|c|c|c|c|c|}
\hline \multirow[b]{2}{*}{ Sample } & \multicolumn{2}{|c|}{ Experimental conditions } & \multicolumn{7}{|c|}{ Hydrostatic pressure $(\mathrm{cm})$} \\
\hline & $\begin{array}{l}\text { Antimicrobial } \\
\text { finish (\%) }\end{array}$ & $\begin{array}{l}\text { Water repellent } \\
\text { finish (\%) }\end{array}$ & 0 wash & 1 wash & 2 wash & 5 wash & 10 wash & 15 wash & 20 wash \\
\hline \multirow[t]{4}{*}{$\bar{A}$} & 1.5 & 4 & 24.4 & 22.3 & 22.1 & 21.0 & 20.2 & 18.3 & 16.3 \\
\hline & 1.5 & 7 & 28.0 & 26.1 & 25.7 & 23.5 & 21.3 & 19.6 & 19.7 \\
\hline & 3 & 4 & 26.6 & 23.9 & 23.6 & 22.0 & 20.3 & 20.0 & 19.5 \\
\hline & 3 & 7 & 29.7 & 25.8 & 24.2 & 23.7 & 23.0 & 21.1 & 20.3 \\
\hline \multirow[t]{4}{*}{ B } & 1.5 & 4 & 22.3 & 21.0 & 21.2 & 20.3 & 18.8 & 17.2 & 14.3 \\
\hline & 1.5 & 7 & 23.9 & 21.3 & 21.0 & 20.6 & 18.5 & 15.6 & 13.1 \\
\hline & 3 & 4 & 23.0 & 21.4 & 19.6 & 19.2 & 17.6 & 15.1 & 13.5 \\
\hline & 3 & 7 & 24.2 & 22.3 & 19.7 & 19.1 & 17.9 & 16.3 & 14.2 \\
\hline \multirow[t]{4}{*}{ D } & 1.5 & 4 & 25.9 & 23.8 & 23.5 & 23.0 & 21.5 & 19.8 & 17.2 \\
\hline & 1.5 & 7 & 26.9 & 24.1 & 23.7 & 23.1 & 22.3 & 21.3 & 20.2 \\
\hline & 3 & 4 & 26.0 & 23.7 & 23.0 & 22.6 & 21.9 & 19.5 & 18.1 \\
\hline & 3 & 7 & 29.0 & 26.0 & 25.4 & 22.3 & 21.6 & 19.6 & 18.6 \\
\hline \multirow[t]{4}{*}{$E$} & 1.5 & 4 & 29.5 & 27.6 & 27.0 & 26.3 & 23.9 & 21.5 & 20.4 \\
\hline & 1.5 & 7 & 34.7 & 31.2 & 29.3 & 28.4 & 25.9 & 23.4 & 22.7 \\
\hline & 3 & 4 & 29.0 & 27.3 & 26.0 & 24.7 & 22.7 & 21.0 & 19.3 \\
\hline & 3 & 7 & 36.0 & 32.0 & 31.2 & 28.6 & 26.1 & 23.7 & 22.2 \\
\hline \multirow[t]{4}{*}{$\mathrm{F}$} & 1.5 & 4 & 21.4 & 20.9 & 20.1 & 18.8 & 16.5 & 15.1 & 13.9 \\
\hline & 1.5 & 7 & 23.1 & 21.0 & 21.0 & 19.3 & 17.4 & 15.3 & 14.7 \\
\hline & 3 & 4 & 22.0 & 20.2 & 20.0 & 19.4 & 16.9 & 14.6 & 13.4 \\
\hline & 3 & 7 & 24.0 & 21.6 & 21.4 & 20.1 & 17.8 & 16.7 & 14.1 \\
\hline
\end{tabular}


polyester-cotton plain woven fabrics treated with $4 \%$ and $7 \%$ fluoropolymer loose their liquid barrier properties and could not maintain AAMI level-2 protection even upto 10 washing cycles. $200 \mathrm{~g} / \mathrm{m}^{2}$ cotton plain fabrics treated with $7 \%$ fluoropolymer maintain their liquid barrier properties for AAMI level-2 protection upto 15 washing cycles. $200 \mathrm{~g} / \mathrm{m}^{2}$ cotton twill fabrics treated with $4 \%$ and $7 \%$ fluoropolymer maintain their liquid barrier properties for AAMI level-2 protection even after 20 washing cycles. $200 \mathrm{~g} / \mathrm{m}^{2}$ cotton satin fabrics treated with $4 \%$ and $7 \%$ fluoropolymer loose their liquid barrier properties for level-2 protection after 5 washing cycles.

\section{Antibacterial activity}

Table 3 shows the results of antibacterial activity on untreated fabrics, whereas Table 6 shows the results of antibacterial activity on the fabric samples treated with different levels of fluoropolymer and antibacterial finishes.

It is observed that fabric samples with $1.5 \%$ and $3 \%$ antibacterial finish pass the antibacterial activity test. Figure 2 (a-b) shows the antibacterial activity test on polyestercotton fabrics without antibacterial finish and with $1 \%$ antibacterial finish respectively. It is observed that the bacterial growth is not inhibited by both the samples. Untreated fabrics show the growth of bacteria in the streaks of the inoculums, spread beyond the parallel streaks and even beneath the fabric sample, whereas $1 \%$ antibacterial finish on the fabric shows spreading of bacteria in the parallel streaks only.

Figure 2 (c-d) shows the bacterial inhibition under the fabric samples for $1.5 \%$ and $3 \%$ concentration for plain cotton fabric samples. The antibacterial finished fabric inhibits bacterial growth beneath the fabric. $1.5 \%$ or greater concentration levels of the antibacterial finish on all the fabrics is sufficient to inhibit the growth of S. aureus. Further, it is observed that the effectiveness of the antibacterial finish is not influenced by the level of fluoropolymer finish. The type of fabric had also no influence on the effectiveness of the antibacterial finish necessary to achieve the antibacterial activity. Further it is observed that all the fabrics used in study treated with 1.5 and $3 \%$ concentration level of antibacterial finishes maintain their effectiveness even after 20 washing cycles.

\section{Air permeability}

Among $150 \mathrm{~g} / \mathrm{m}^{2}$ fabrics of different materials (i.e. sample A, B and C) air permeability is highest for $100 \%$ polyester filament fabric because of smooth and hairiness free yarns (Table 3). Hairy yarns in $100 \%$ cotton and cotton blends offers more resistance to air flow and therefore lead to lower air permeability. Among plain, twill and satin fabrics of $200 \mathrm{~g} / \mathrm{m}^{2}$ weight (i.e. sample D, E and F), satin woven fabric offers highest air permeability, whereas twill fabric shows the least. This is due to the longer floats and larger pore sizes (Table 2) in satin structure. Twill fabric with compact structure offer the lowest air permeability. Further, air permeability decreases as the fabric weight increases due to compact structure with smaller pores and higher thickness.

It was observed that the air permeability decreases on the application of antibacterial and fluoropoylmer finish for all samples (Table 7). The results are statistically significant at $95 \%$ confidence level. The application of chemical finishes over the fabric surface results in blocking of some pores, which may be responsible for the reduction of air permeability. 
Table 6 Fabric thickness and antibacterial activity of finished fabric samples

\begin{tabular}{|c|c|c|c|c|c|c|c|c|c|c|c|c|c|c|}
\hline & \multicolumn{2}{|l|}{ Experimental conditions } & \multicolumn{6}{|c|}{ Fabric thickness (mm) } & \multicolumn{6}{|c|}{ Antibacterial activity } \\
\hline & Antibacterial finish (\%) & Water repellent finish (\%) & $\bar{A}$ & B & $\mathrm{C}$ & $\mathbf{D}$ & $\mathrm{E}$ & $\mathrm{F}$ & $\bar{A}$ & B & $\mathrm{C}$ & D & $E$ & $F$ \\
\hline 1. & 0 & 1 & 0.236 & $0.309^{*}$ & 0.309 & 0.600 & $0.540^{*}$ & $0.504 \#$ & - & - & - & - & - & - \\
\hline 2. & 0 & 4 & $0.237^{*}$ & $0.312^{*}$ & 0.312 & $0.601 *$ & $0.541^{*}$ & $0.507^{*}$ & - & - & - & - & - & - \\
\hline 3. & 0 & 7 & 0.241 & $0.316^{*}$ & 0.317 & $0.603^{*}$ & 0.543 & 0.514 & - & - & - & - & - & - \\
\hline 4 & 1 & 1 & $0.234 \#$ & 0.308 & 0.313 & 0.599 & 0.539 & 0.509 & - & - & - & - & - & - \\
\hline 5. & 1 & 4 & $0.237 \#$ & 0.315 & $0.315^{*}$ & $0.603^{*}$ & $0.547^{*}$ & 0.517 & - & - & - & - & - & - \\
\hline 6. & 1 & 7 & 0.241 & 0.322 & 0.319\# & $0.608^{*}$ & 0.548 & 0.518 & - & - & - & - & - & - \\
\hline 7. & 1.5 & 1 & 0.232 & 0.310 & 0.310 & 0.620 & 0.541 & 0.514 & Pass & Pass & Pass & Pass & Pass & Pass \\
\hline 8. & 1.5 & 4 & 0.234 & $0.317^{*}$ & $0.311^{*}$ & $0.619^{*}$ & $0.546^{*}$ & 0.520 & Pass & Pass & Pass & Pass & Pass & Pass \\
\hline 9. & 1.5 & 7 & 0.241 & 0.319 & 0.321 & 0.623 & 0.550 & $0.524^{*}$ & Pass & Pass & Pass & Pass & Pass & Pass \\
\hline 10. & 3 & 1 & $0.232 \#$ & 0.312 & 0.310 & 0.610 & 0.540 & 0.510 & Pass & Pass & Pass & Pass & Pass & Pass \\
\hline 11. & 3 & 4 & 0.241 & 0.319 & 0.316 & 0.620 & 0.554 & 0.520 & Pass & Pass & Pass & Pass & Pass & Pass \\
\hline 12. & 3 & 7 & 0.249 & $0.322^{*}$ & $0.321 \#$ & 0.623 & $0.561^{*}$ & $0.526^{*}$ & Pass & Pass & Pass & Pass & Pass & Pass \\
\hline 13. & 1 & 0 & $0.232 \#$ & 0.304 & $0.306 \#$ & 0.588 & $0.530 \#$ & 0.510 & - & - & - & - & - & - \\
\hline 14. & 1.5 & 0 & $0.232^{*} \#$ & 0.305 & 0.310 & 0.590 & $0.533^{*}$ & 0.514 & Pass & Pass & Pass & Pass & Pass & Pass \\
\hline 15 & 3 & 0 & 0.236 & 0.309 & 0.312 & 0.610 & 0.541 & 0.520 & Pass & Pass & Pass & Pass & Pass & Pass \\
\hline 16. & 0 & 0 & 0.232 & 0.304 & 0.303 & 0.582 & 0.531 & 0.500 & - & - & - & - & - & - \\
\hline
\end{tabular}

Note: (-) Sign means the fabric samples fails the test. 


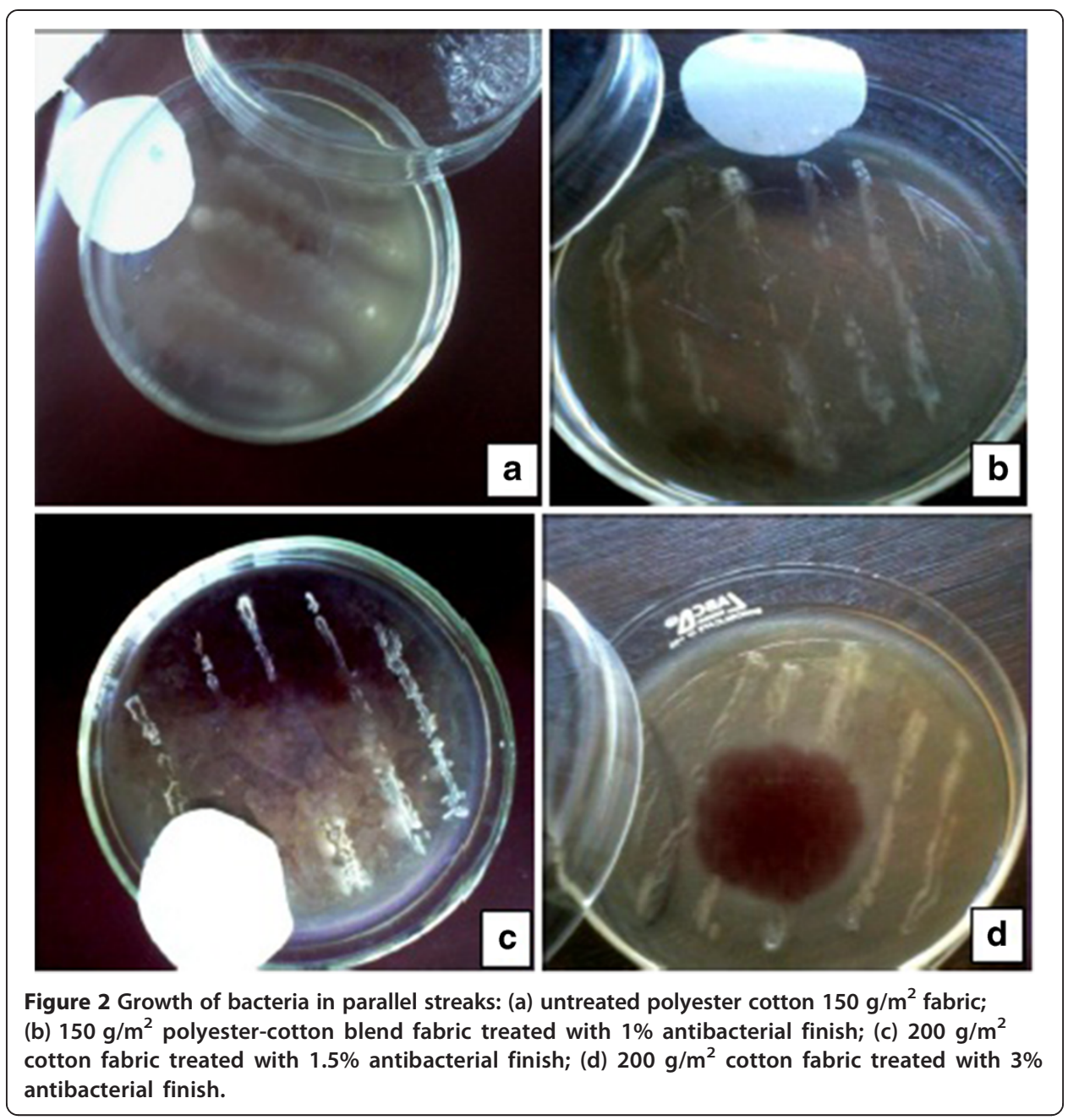

\section{Fabric stiffness force}

$150 \mathrm{~g} / \mathrm{m}^{2}$ plain fabrics (i.e. sample A, B and C) do not show any significant difference in their fabric stiffness. Among plain, twill and satin fabrics of $200 \mathrm{~g} / \mathrm{m}^{2}$ weight (i.e. sample D, E and F), it is observed that satin fabric with longer floats and few interlacement points offer lower stiffness than plain and twill fabrics. More regular pattern in plain weave and diagonal line pattern in twill weave make the fabric stiffer. Heavier fabric with coarser yarns offers higher stiffness as compared to lighter fabrics. Further, the stiffness force increases with increasing concentration level of antibacterial and fluoropolymer finishes for all fabric samples which may be due to increase in fabric thickness. Results are statistically significant at $95 \%$ confidence level. The fabric samples shows highest stiffness at concentration level of $3 \%$ antibacterial finish and $7 \%$ of fluoropolymer finish.

Out of $100 \%$ polyester, polyester-cotton and $100 \%$ cotton plain woven fabric samples of weight $150 \mathrm{~g} / \mathrm{m}^{2}, 100 \%$ polyester fabric shows least stiffness and highest air permeability value.Twill fabrics are less comfortable as compared to plain and satin fabrics, because of their higher stiffness and lower air permeability values. Satin fabric offers the highest air permeability and lowest stiffness force but shows least barrier protection. 
Table 7 Air permeability and stiffness properties of treated fabric samples

\begin{tabular}{|c|c|c|c|c|c|c|c|c|c|c|c|c|c|c|}
\hline & \multicolumn{2}{|l|}{ Experimental conditions } & \multicolumn{6}{|c|}{ Air permeability $\left(\mathrm{cm}^{3} / \mathrm{cm}^{2} / \mathrm{sec}\right)$} & \multicolumn{6}{|c|}{ Stiffness force (N) } \\
\hline & Antibacterial finish (\%) & Water repellent finish (\%) & $\bar{A}$ & B & C & D & $\mathrm{E}$ & $\mathrm{F}$ & $\bar{A}$ & B & $\mathrm{C}$ & D & $\mathrm{E}$ & $\mathrm{F}$ \\
\hline 1 & 0 & 1 & 6.51 & 6.06 & 5.62 & 4.55 & $2.95 \#$ & 12.43 & 1.03\# & 1.07 & 1.13\# & $2.43 \#$ & 3.10 & 2.20 \\
\hline 2 & 0 & 4 & 6.09 & 5.87 & 5.18 & 4.38 & 2.84 & 12.13 & $1.10 \#$ & 1.20 & 1.20 & 2.50 & 3.40 & 2.33 \\
\hline 3 & 0 & 7 & 5.83 & 5.69 & 5.15 & 4.27 & 2.69 & 11.25 & $1.15^{*}$ & 1.28 & 1.40 & 3.10 & 3.90 & 2.63 \\
\hline 4 & 1 & 1 & 6.21 & 5.93 & 5.39 & 4.54 & 2.84 & 12.15 & 1.15 & 1.20 & 1.27 & 2.70 & 3.40 & 2.44 \\
\hline 5 & 1 & 4 & 5.94 & 5.89 & $5.32^{*}$ & 4.40 & 2.81 & $12.10^{*}$ & $1.18^{*}$ & 1.22 & 1.40 & 2.87 & $3.50^{*} \#$ & 2.50 \\
\hline 6 & 1 & 7 & 5.56 & 5.64 & 5.15 & 4.21 & 2.81 & 11.69 & $1.20^{*}$ & 1.30 & $1.43^{*}$ & 3.60 & 3.90 & 2.70 \\
\hline 7 & 1.5 & 1 & 6.25 & 5.87 & 5.34 & 4.44 & 2.87 & 12.31 & 1.28 & 1.32 & 1.30 & 2.90 & 3.50\# & 2.67 \\
\hline 8 & 1.5 & 4 & 5.93 & 5.77 & 5.32 & 4.25 & 2.80 & 11.68 & 1.38 & 1.40 & 1.40 & 3.60 & 4.10 & 2.83 \\
\hline 9 & 1.5 & 7 & 5.85 & 5.58 & 5.23 & 4.15 & 2.61 & 11.55 & 1.50 & 1.47 & 1.73 & 3.72 & 4.60 & 3.20 \\
\hline 10 & 3 & 1 & 6.13 & 5.74 & 5.31 & 4.33 & 2.89 & 11.62 & 1.30 & 1.30 & 1.53 & 3.60 & 4.00 & 2.90 \\
\hline 11 & 3 & 4 & 5.83 & 5.66 & $5.29^{*}$ & 4.21 & 2.78 & 11.45 & 1.48 & 1.53 & 1.67 & $3.60^{*}$ & 4.40 & $3.00^{*}$ \\
\hline 12 & 3 & 7 & $5.82^{*}$ & 5.61 & 5.18 & 4.13 & 2.55 & 11.36 & 1.80 & 2.00 & 2.06 & 3.93 & 4.80 & 3.50 \\
\hline 13 & 1 & 0 & 6.53 & 6.09 & 5.74 & 4.59 & 2.89 & 12.55 & 1.03\# & 1.02\# & 1.10\# & 2.63 & 3.40 & 2.20 \\
\hline 14 & 1.5 & 0 & 6.47 & 5.90 & 5.62 & 4.54 & 2.83 & 12.43 & 1.13 & 1.10 & 1.20 & 3.10 & 3.70 & 2.48 \\
\hline 15 & 3 & 0 & 6.39 & $5.85^{*}$ & 5.31 & 4.47 & 2.69 & 11.23 & 1.23 & 1.20 & 1.30 & 3.30 & 4.20 & $2.53^{*}$ \\
\hline 16 & 0 & 0 & 6.62 & 6.17 & 5.86 & 4.67 & 2.98 & 13.29 & 1.05 & 1.02 & 1.10 & 2.43 & 2.90 & 2.10 \\
\hline
\end{tabular}

Note: '*' means results are statistically insignificant at $95 \%$ confidence level with respect to finish level \& ' $\#$ ' means results are statistically insignificant at $95 \%$ confidence level with respect to untreated fabrics. 


\section{Conclusion}

Plain, twill and satin woven fabrics of cotton, polyester and polyester-cotton of $150 \mathrm{~g} / \mathrm{m}^{2}$ and $200 \mathrm{~g} / \mathrm{m}^{2}$ have been used to study their suitability for surgical gowns before and after application of flouropolymer and antibacterial finishes. Different concentration levels of fluoropolymer and antibacterial finishes were used to find the level of finishes required for different AAMI protection levels along with their durability using standard laundering cycles. It is observed that all the fabrics except $150 \mathrm{~g} / \mathrm{m}^{2}$ cotton fabric, can be used for AAMI protection level 1 only without any finish. The water repellence of fabrics increases on application of fluoropolymer finish. $4 \%$ fluoropolymer finish on these fabrics can be used to make them suitable for AAMI protection level 2. Increasing fluropolymer concentration level further increases the hydrostatic pressure but does not make them suitable for protection level 3 and therefore are not recommended for critical areas of the surgical gown. Twill woven fabrics of $200 \mathrm{~g} / \mathrm{m}^{2}$ show highest hydrostatic pressure, but higher stiffness and low air permeability make them quite uncomfortable for longer duration usage. Satin fabrics are more comfortable offering higher air permeability and lower stiffness, but show lowest hydrostatic pressure values and therefore offer minimal water repellence. Repeated laundering cycles lead to reduction in the barrier resistance of fabrics. It is observed that $150 \mathrm{~g} / \mathrm{m}^{2}$ polyester and twill woven $200 \mathrm{~g} / \mathrm{m}^{2}$ cotton fabrics with $4 \%$ fluoropolymer finish maintain their AAMI protection level 2 upto 20 washing cycles. Satin woven fabrics treated with $4 \%$ fluoropolymer finish can maintain AAMI protection level 2 upto 5 washing cycles only. 1.5\% antibacterial finish is sufficient to inhibit the growth of $S$. aureus bacteria for all fabric samples and this antibacterial activity is maintained upto 20 washing cycles for all fabrics.

Competing interests

The authors declare that they have no competing interests.

Authors' contributions

VKM and RV contributed to the conception and design of the study, and analysis of data. VM contributed to procurement of bacteria and antibacterial testing of the fabrics. All authors prepared and approved the final manuscript.

Author details

${ }^{1}$ Department of Textile Technology, National Institute of Technology, Jalandhar, India. ${ }^{2}$ Department of Chemical Engineering, National Institute of Technology, Jalandhar, India.

Received: 5 July 2014 Accepted: 7 August 2014

Published online: 03 October 2014

References

Association for the Advancement of Medical Instrumentation. (2003). Liquid barrier performance and classification of protective apparel and drapes intended for use in health care facilities (Association for the Advancement of Medical Instrumentationth ed.). Arlington, VA: ANSI/AAMI PB70.

Behera, BK, \& Arora, H. (2009). Surgical Gown: A Critical Review. Journal of Industrial Textiles, 38(3), 205-231.

Brock, TD, Madigan, MT, \& Martinko, JM. (1994). Biology of Microorganisms (7th ed.). New Jersey: Prentice Hall.

Centers for Disease Control. (1998). Perspectives in disease prevention and health promotion update: universal precautions for prevention of transmission of HIV, HBV and otherblood borne pathogens in health care settings. MMWR, 37, 373-387.

Garibaldi, RA, Maglio, AM, Lerer, T, Becker, DB, \& Lyons, R. (1986). Comparison of nonwoven and woven gown and drape fabric to prevent intraoperative wound contamination and post operative infection. American Journal of Surgery, 152, 505-507.

Gupta, BS. (1998). Effect of structural factors on absorbent characteristics of nonwovens. In Proceedings TAPPI Nonwovens Conference (pp. 195-202).

Huang, W, \& Leonas, K. (2000). Evaluating a one bath process for imparting antibacterial activity and repellency to nonwoven surgical gown fabrics. Textile Research Journal, 70, 774-782.

Lankester, BJA, Bartlett, GE, Garneti, N, Blom, AW, Bowker, KE, \& Bannister, GC. (2002). Direct measurement of bacterial penetration through surgical gown: a new method. Journal of Hospital Infection, 50(4), 281-285.

Laufman, H, Eudy, WW, Vandernoot, AM, Liu, D, \& Harris, CA. (1975). Strikethrough of moist contamination by woven and nonwoven surgical materials. Annals of Surgery, 181, 857-862. 
Laufman, H, Seigal, JD, \& Edberg, SC. (1979). Moist bacterial strike through of surgical material: Confirmatory tests. Annals of Surgery, $189,68-74$.

Leonas, KK. (1997). Using laser scanning confocal microscopy to evaluate microorganism transmission through surgical gown fabrics. In Proceedings, Medical Textiles '96 Conference (pp. 60-65).

Leonas, KK. (1998). Effect of laundering on the barrier properties of reuseable gown fabric. American Journal of Infection Control, 26, 495-501.

Leonas, KK, \& Jinkins, RS. (1997). The relationship of selected fabric characteristics and the barrier effectiveness of surgical gown fabric. American Journal of Infection Control, 25, 16-23.

Leonas, KK, \& Miller, EM. (1990). Transmission of two bacterial species through selected fabrics-nonwoven and woven. INDA Journal of Nonwovens Research, 2, 29-32.

Midha, VK, Dakuri, A, \& Midha, V. (2012). Studies on the properties of nonwoven surgical gowns. Journal of Industrial Textiles, 43(2), 174-190

Olderman, GM. (1984). Liquid repellency and surgical fabric barrier materials. Journal of Industrial Textiles, 3, 30-41.

Pamuk, O, Ondogan, Z, \& Abreu, MJ. (2009). The thermal comfort properties of reusable and disposable surgical gown fabrics. Tekstilec, 52(1-3), 24-30.

Parthasarathi, V. \& Thilagavathi, G. (2011). A Review on antiviral and antibacterial surgical gown and drapes. Indian Journal of Fundamental and Applied Life Sciences, 1, 215-218.

Rutala, WA, \& Weber, DJ. (2001). A review of single use and reusable gowns and drapes in health care. Infection Control and Hospital Epidemiology, 22, 248-257.

Slater, K. (1998). Textile use in surgical gown design. Canadian Textile Journal, 115, 16-28.

Smith, JW, \& Nichols, RL. (1991). Barrier efficiency of surgical gowns: Are we really protected from our patients's pathogens. Archives of Surgery, 126, 756-763.

Virk, RK, Ramaswamy, GN, Bourham, M, \& Bures, BL. (2004). Plasma and antimicrobial treatment of nonwoven fabrics for surgical gowns. Textile Research Journal, 74(12), 1073-1079.

doi:10.1186/s40691-014-0012-7

Cite this article as: Midha et al.: Durability of fluoropolymer and antibacterial finishes on woven surgical gown fabrics. Fashion and Textiles 2014 1:12.

Submit your manuscript to a SpringerOpen ${ }^{\circ}$ journal and benefit from:

- Convenient online submission

- Rigorous peer review

- Immediate publication on acceptance

- Open access: articles freely available online

- High visibility within the field

- Retaining the copyright to your article

Submit your next manuscript at $\boldsymbol{\nabla}$ springeropen.com 